\title{
REMOTE SENSING \& GIS INTEGRATION FOR MONITORING THE AREAS AFFECTED BY FOREST FIRES: A CASE STUDY IN IZMIR, TURKEY
}

\author{
E. Çolak ${ }^{1}$, A. F. Sunar ${ }^{2}$ \\ ${ }^{1}$ ITU, Civil Engineering Faculty, Geomatics Engineering Graduate Program, 80626 Maslak Istanbul, Turkey \\ colakem@itu.edu.tr \\ ${ }_{2}^{2}$ ITU, Civil Engineering Faculty, Geomatics Engineering Department, 80626 Maslak Istanbul, Turkey \\ fsunar@itu.edu.tr
}

KEY WORDS: Remote Sensing, Forest Fire, Burn Indexes, Classification, Sentinel, Landsat, DEM.

\begin{abstract}
:
A forest fire is stated as an ecological disaster whether it is man-made or caused naturally. İzmir is one of the regions where forest fires are most intensified in Turkey. The study area located at Aegean region of Turkey suffered two forest fires in 2017; Menderes and Bayindır areas. This study presents the integration of remote sensing (Sentinel 2 and Landsat 8 satellite images) and GIS data to map and evaluate the forest burned areas due to both forest fires. For this purpose, different indexes such as Burn Area Index (BAI), Mid Infrared Burn Index (MIRBI), Normalized Burn Ratio (NBR) and Normalized Burn Ratio Thermal (NBRT) Burn Index are applied besides different classification algorithms. The results showed that different vegetation types/zones are being affected. Sentinel 2 and Landsat 8 data are integrated to the GIS established with fieldwork data to analyse and also validate the results. Digital Elevation Model (DEM) data produced from ASTER satellite is also overlaid to the outcomes to emphasize the destructed forest areas. The efficiency of using two different satellites are outlined by comparing the accuracy of forest fire maps produced.
\end{abstract}

\section{INTRODUCTION}

Forest fires affect the terrestrial ecosystem and the atmospheric system significantly that contribute to deforestation, greenhouse gas emission, and also damage on human well-being. Its effects can be minor or major in forest ecosystems depending on their intensity and result in stand's species composition and structure changes (Gonçalves and Sousa 2017).

Fires are common in many forest systems around the world, and also one of the primordial factors affecting the particularly Mediterranean-type ecosystems, causing more destruction to trees than all the other hazards, such as diseases, insects, wind throws, and frosts (Gonçalves and Sousa 2017). Since being situated in the Mediterranean region, the number of annual forest fires in Turkey is very high (Figure 1). According to General Directorate of Forestry of Turkey, the total number of forest fire was 3188 , more than $90 \%$ due to human activity and less than $10 \%$ are caused naturally, in the year 2016 . The total devastation of these fires was 9156 ha. These fires are occurred $65 \%$ in productive high forest areas which mainly affect the biodiversity. Man-made fires are mainly classified as intentional and unintentional fires (Sunar and Özkan, 2001). Cigarettes, hunting and picnics are the fundamental reasons of unintentional fires, while terror attacks, incension and expanding are mostly connected to intentional fires.

Fires occurring as a result of natural causes can be different from one region to another depending on the vegetation types, weather, climate and topography. Especially forests in Mediterranean and Aegean regions of Turkey is mainly affected by weather conditions (Akkaş et al., 2006). In addition to high temperatures, relative humidity and wind speed in these regions are also important parameters that effects the fire.

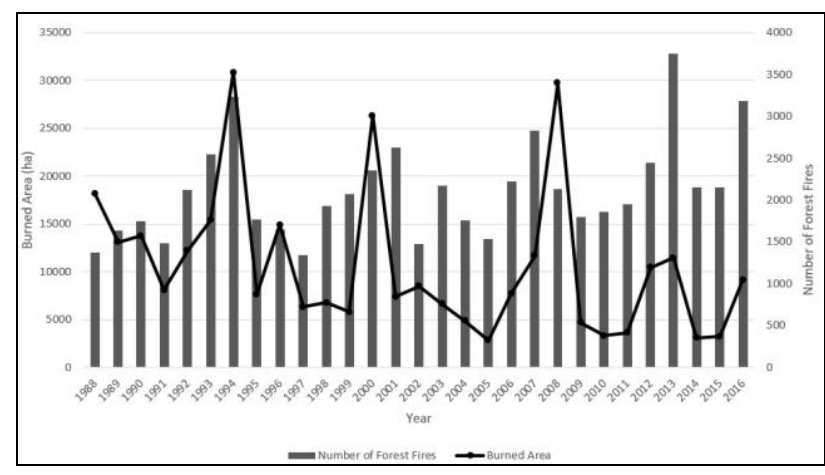

Figure 1. Number of forest fires and burned total area in Turkey (General Directorate of Forestry, 2017).

Remote sensing and Geographic Information Systems (GIS) are the most practical and efficient tools for fire monitoring and mapping at local, regional and global scales. Forest fires, an important research topic of remote sensing, have been used comprehensively for improving and testing new image analysis techniques and GIS models (Gitas el al., 2014).

In this study, the environmental consequences and impacts of the forest fire that took place in Menderes region of İzmir was analysed with an integrated remote sensing and GIS data acquired after the forest fire, and post-fire forest map was integrated with the forest management plans in the GIS. 


\section{STUDY AREA}

The fire occurred within the border of the Izmir Forestry Chief Directorate which is located in the Aegean area of Turkey (Figure 2). The fire in Menderes started on 1 July, 2017 in the maquis area and continued for 4 days till 5 July, 2017.

Menderes region is covered with Calabrian Pine (Pinus brutia). The elevation changes between $90 \mathrm{~m}$ and $450 \mathrm{~m}$, and the slope is between $5-65 \%$. The average temperature on 1 July, 2017 was $35^{\circ} \mathrm{C}$ and maximum temperature was $42^{\circ} \mathrm{C}$.

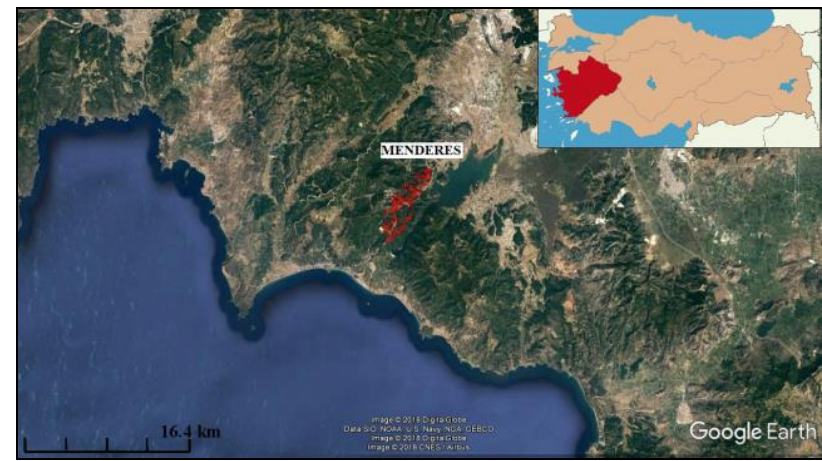

Figure 2. The image of the study area (CGoogle Earth).

Meteorological data (mean and maximum wind velocity, wind direction, mean relative humidity (\%), mean air temperature $\left({ }^{\circ} \mathrm{C}\right)$, mean atmospheric pressure) were obtained from the meteorological station located in Menderes region. The wind was usually blown from the North and Northeast throughout the day and the average wind speed was $7 \mathrm{~m} / \mathrm{s}$ (Figure 3 ).

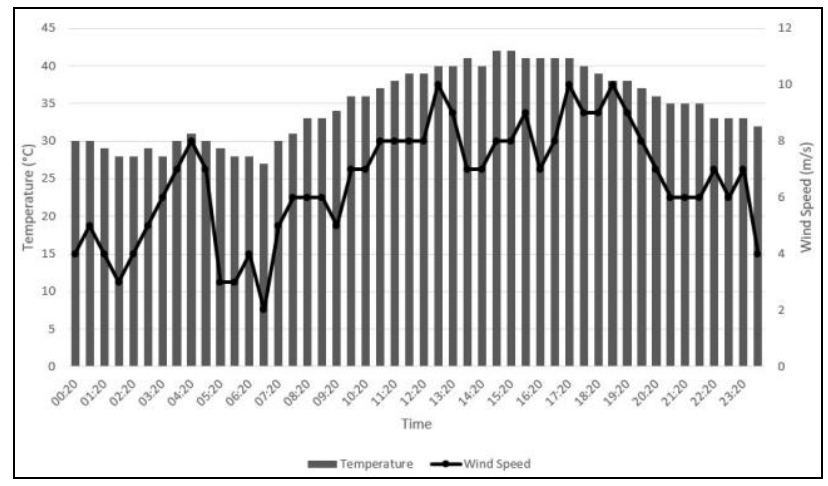

Figure 3. Weather temperature and wind speed of Menderes area on 1 July, 2017 (Meteorological Service, 2017).

It is considered that high weather temperature and wind speed caused to initiate the forest fire in the Menderes area of Izmir (Table 1). As known, winds that have a speed between $3-9 \mathrm{~m} / \mathrm{s}$ have been observed to cause large forest fires (Akkaş et al., 2006). The mean relative humidity in the area was $30 \%$ during the fire.

Menderes area includes partly rocky terrain. These areas were also affected by fire but were not added into the burning area boundary since they were not regarded as forest (Figure 4).

\begin{tabular}{|l|c|c|}
\hline Parameters & Optimum values & $\begin{array}{c}\text { Mean values in } \\
\text { Menderes area }\end{array}$ \\
\hline Temperature & $>25^{\circ} \mathrm{C}$ & $35^{\circ} \mathrm{C}$ \\
Wind Speed & $3-8,8 \mathrm{~m} / \mathrm{s}$ & $7 \mathrm{~m} / \mathrm{s}$ \\
Humidity & $<40 \%$ & $30 \%$ \\
\hline
\end{tabular}

Table 1. Meteorological parameters causing or affecting a forest fire in Turkey (Akkaş et al., 2006).

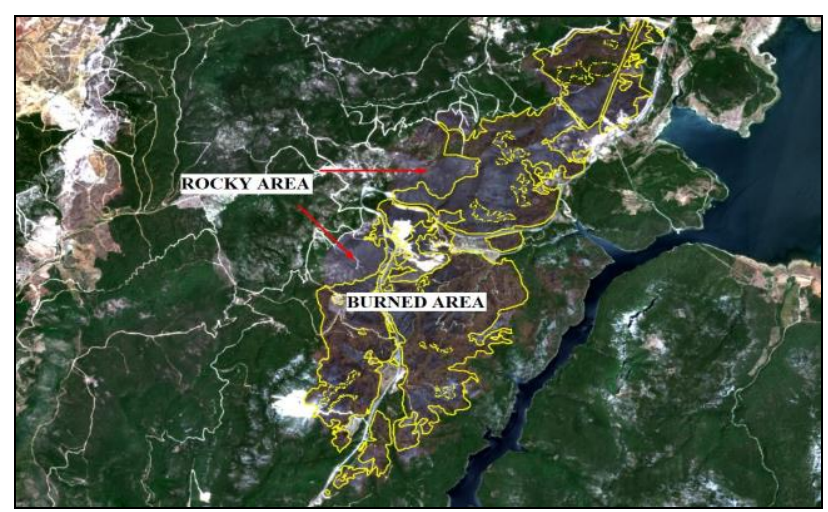

Figure 4. Burned and rocky forest areas in the study area.

\section{DATA COLLECTION}

Cloud - free Sentinel 2 and Landsat 8 images acquired after the fire (22 July 2017 and 16 July 2017, respectively) were used in the analyse. For Landsat 8, the bands between 2 and 7 which have $30 \mathrm{~m}$ spatial resolution and for Sentinel, the bands; 2, 3, 4 and 8 which have $10 \mathrm{~m}$ spatial resolution were used. Besides the visible bands of Sentinel having $10 \mathrm{~m}$ spatial resolution were also sampled to $20 \mathrm{~m}$ spatial resolution and were used with other original $20 \mathrm{~m}$ resolution bands $(5,6,7$ and $8 \mathrm{a})$ to evaluate the efficiency of the spatial resolution on thematic mapping.

The spatial and spectral characteristics of the Landsat 8 and Sentinel data used are shown in Figure 5.

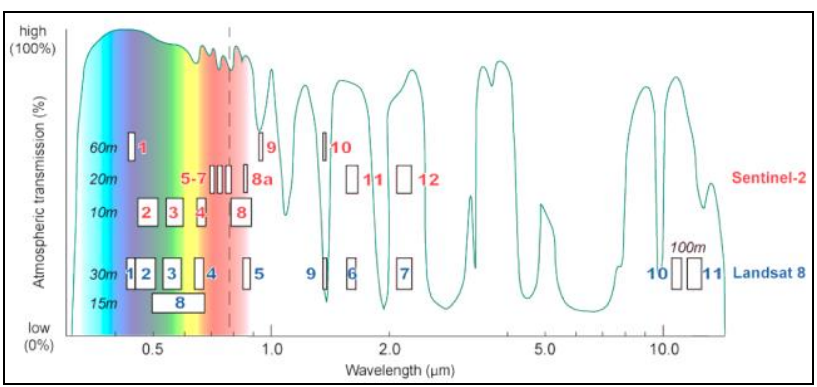

Figure 5. The spatial and spectral characteristics of the Landsat 8 and Sentinel data (Kääb et al., 2006).

A GIS data prepared by the Izmir Forestry Directorate Office which showing the vegetation types, canopy density and slope in the burned area was integrated with remotely sensed data.

\section{APPLICATION}

Different image processing steps such as spectral burn indices, classification and integration with GIS data have been applied 
to evaluate the consequences of the forest fire both quantitatively and qualitatively.

\subsection{Spectral Burn Indices}

Information about target features can be improved, isolated and analysed when brightness values of multiple bands integrated in mathematical algorithms. Spectral burn indices supply an optimum measure and beneficial signal for fire effects (Key and Benson, 2005). Hence, several spectral burn indexes named as Burn Area Index (BAI), Normalized Burn Ratio (NBR) and Normalized Burn Ratio - Thermal (NBRT) and Mid-Infrared Burn Index (MIRBI) were applied to Landsat 8 satellite image (Key and Benson, 2005; Holden et al., 2005; Schepers et al., 2014). The formulas of all indexes used are given below:

The Burn Area Index (BAI):

$$
B A I=\frac{1}{(0.1-\text { Red })^{2}+(0.06-N I R)^{2}}
$$

The Normalized Burn Ratio (NBR):

$$
N B R=\frac{(N I R-S W I R)}{(N I R+S W I R)}
$$

The Normalized Burn Ratio - Thermal (NBRT):

$$
N B R T=\frac{\left(N I R-S W I R\left(\frac{\text { THERMAL }}{1000}\right)\right)}{\left(N I R+S W I R\left(\frac{\text { THERMAL }}{1000}\right)\right)}
$$

The Mid-Infrared Burn Index (MIRBI):

$$
M I R B I=10 L S W I R-9.8 S S W I R+2
$$

\subsection{Image Classification}

For assigning land cover classes to pixels, image classification method known as the most common image processing step is applied to multiband satellite data. In this study, unsupervised and supervised classification methods were applied to produce thematic maps showing the fire effected forest areas.

\subsubsection{Unsupervised Classification}

This classification method is defined as a process of pixels that have similar spectral values. Each group of similar pixels is called as a spectral class. These spectral classes are assumed to correspond to cover type classes such as range type, stand density, timber size classes, and wetland types (Verbyla, 2000).

In this study, Iterative Self-Organizing Data Analysis (ISODATA) algorithm was used as unsupervised classification method on Sentinel 2 and Landsat 8 satellite images. All images are classified with 15 classes. All thematic maps having different spatial resolutions $(10 \mathrm{~m} / 20 \mathrm{~m}$ - Sentinel image and $30 \mathrm{~m}$ - Landsat image) were compared with each other and also with the GIS data obtained from the field study.

\subsubsection{Supervised Classification}

The basic approach in supervised classification is to sample known land cover types to define representative spectral values of each cover type. Each pixel is estimated or classified based on its resemblance to representative cover type spectral values (Verbyla, 2000).

In this study, the Maximum Likelihood classification algorithm was utilized to classify the satellite images. For the training areas selection, the Google Earth Pro and also the GIS data were used as a ground truth data.

\subsection{GIS Analyses}

All possible factors affecting the fire have been revealed by utilizing the GIS data obtained from the field study. In this context, besides the factors related to weather conditions (i.e. weather temperature, wind and humidity), the other factors responsible for forest fire in the study area are considered as vegetation type, slope, and canopy. Hence two main factors (slope and canopy) were mapped (in 1:30 000 scale) and their relationship between the fire were discussed.

\section{RESULTS}

In this study, spectral burn indices (BAI, NBR, NBRT, and MIRBI) were applied to Landsat 8 satellite image dated 16 July, 2017. As seen in Figure 6, burned areas were clearly distinguished from unburned areas. Especially burn indices; BAI (Figure 6a), NBRT (Figure 6d), and MIRBI (Figure 6b) have been separated burned and unburned areas from each other easily. On the other hand, it is observed that the burned forest area (black colour) and the mine area (black colour) in the Normalized Burn Ratio (NBR) index are mixed (Figure 6c).

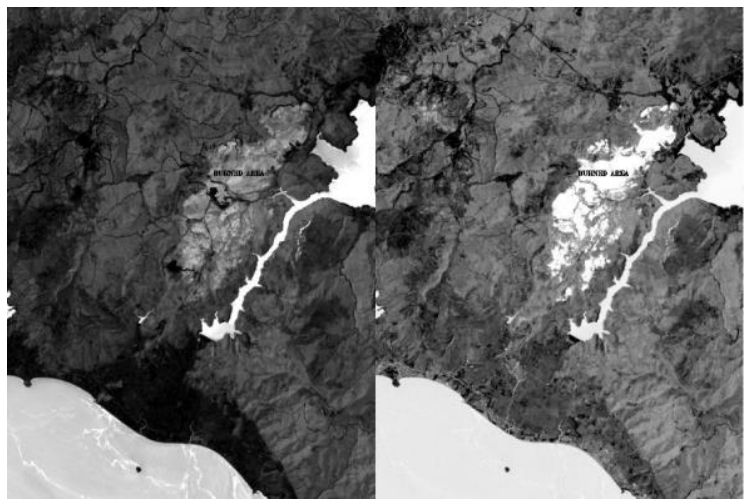

(a)

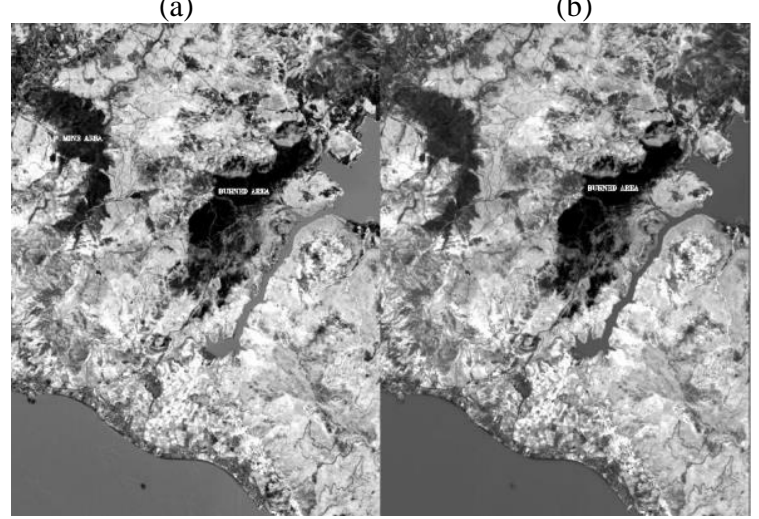

(c) (d)
Figure 7. Spectral Burn Indices. (a) BAI. (b) MIRBI. (c) NBR. (d) NBRT. 
Iterative Self-Organizing Data Analysis (ISODATA) method was used as unsupervised classification on Sentinel 2 and Landsat 8 images. Both images were classified with 15 classes (Figure 8a, 9a, and 10a). The 5 major classes selected in the study area are burned forest area, forest area, bare soil, settlement area, and sea.

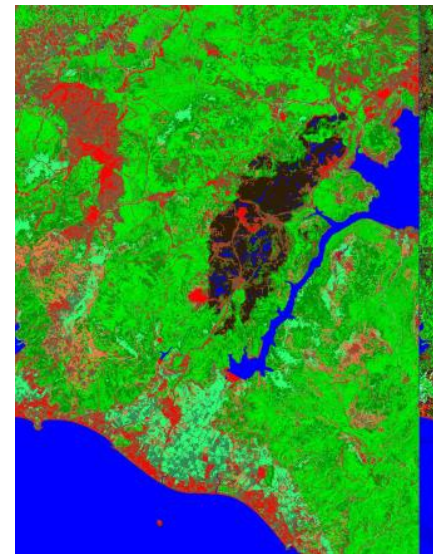

(a)

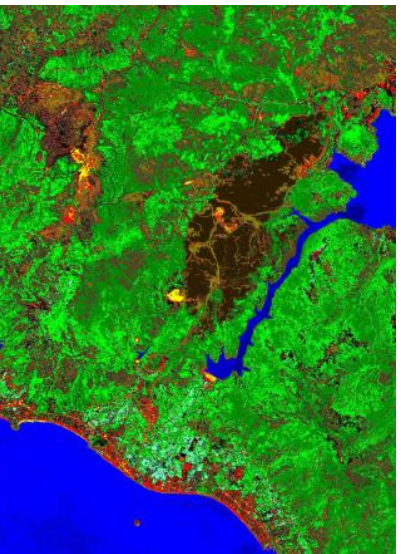

(b)
Figure 8. Sentinel $2 \mathrm{~A}-10 \mathrm{~m}$ classification results. (a) Unsupervised. (b) Supervised.

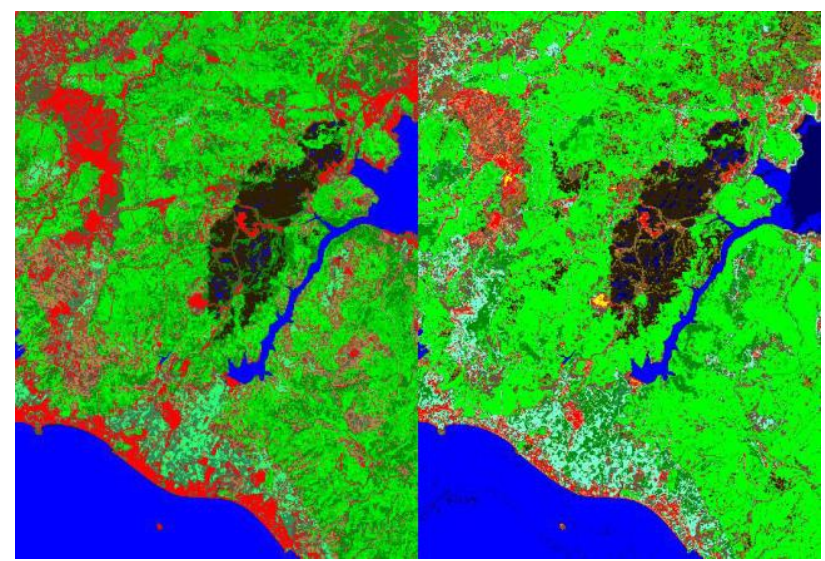

(a)

(b)

Figure 9. Sentinel $2 \mathrm{~A}-20 \mathrm{~m}$ classification results. (a) Unsupervised. (b) Supervised.

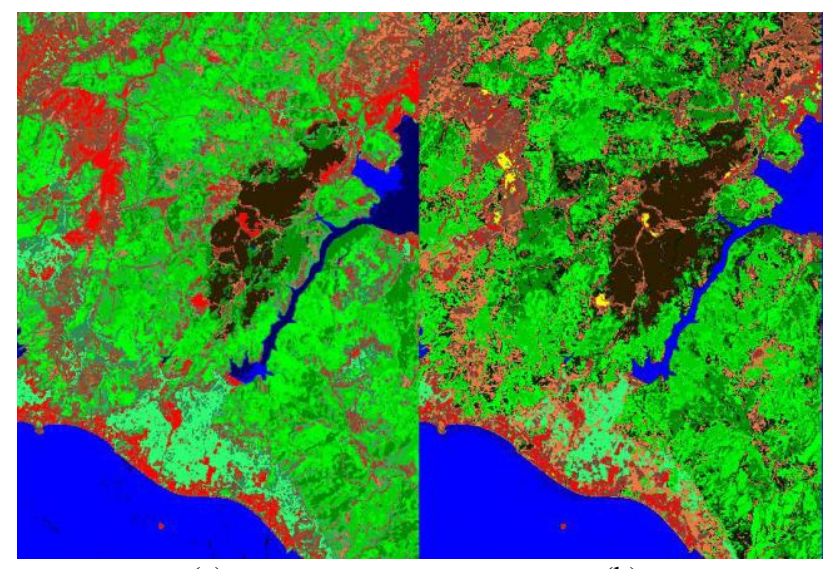

(a)

(b)

Figure 10. Landsat $8-30 \mathrm{~m}$ classification results. (a) Unsupervised. (b) Supervised.
For the supervised classification, the Maximum Likelihood classification method were performed (Figure 8b, 9b, and 10b) and similar to the unsupervised classification, same classes were taken into consideration.

The exact burned forest area obtained after the field study done by Izmir Forestry Chief Directorate is 986 ha. The total forest area within the boundaries of the Menderes Forestry Chief Directorate is 24957 ha. This indicates that the fire destroyed $4 \%$ of the total forest area. Burned areas mapped by the ISODATA classification were found as 972,9 ha 938,61 ha and 926,91 ha, for Sentinel (10 m), Sentinel (20 m) and Landsat (30 $\mathrm{m})$ spatial resolution images, respectively (Figure 11a). The burned forest area mapped by the Maximum Likelihood classification were found as 962,37 ha, 963,36 ha and 911,34 ha for Sentinel $(10 \mathrm{~m})$, Sentinel $(20 \mathrm{~m})$ and Landsat $(30 \mathrm{~m})$, respectively (Figure 11b).

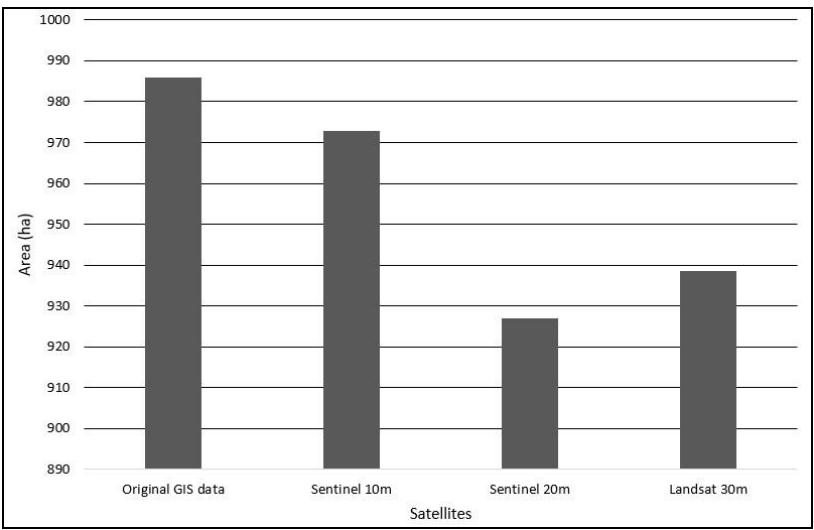

(a)

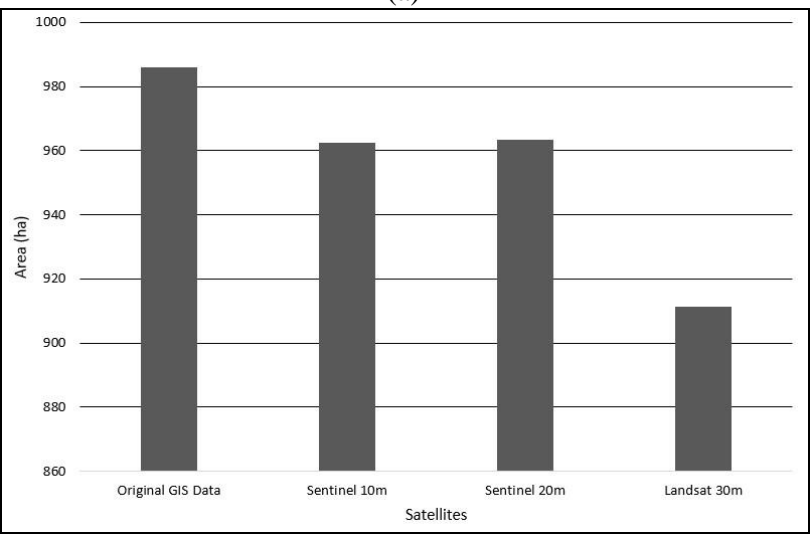

(b)

Figure 11. Comparison of the areal extents of the fire burned areas mapped by different classification method.

(a) Unsupervised classification. (b) Supervised classification.

After the classification process, the efficiencies of Sentinel 2A and Landsat 8 satellites were compared with Overall accuracies and computed as $96.43 \%, 82.22 \%$, and $80.30 \%$ for Sentinel $(10 \mathrm{~m})$, Sentinel $(20 \mathrm{~m})$, and Landsat $(30 \mathrm{~m})$ forest fire maps, respectively. As seen the Sentinel $(10 \mathrm{~m})$ image classification gave the best result in association with the higher spatial resolution.

The vegetation type, canopy, and slope are the most significant parameters that affects the forest fire and this is shown in many research studies (Ribeiro et al., 2014; Başaran, 2004). In Turkey, it is known that forest fires are occurring mostly in 
Black Pine (Pinus nigra) and Calabrian Pine (Pinus brutia) forests because these trees are extreme burnable (Akkaş et al., 2006). As mentioned before, the burned forest in Menderes area is covered only with Calabrian Pine forest type.

It is easier for the fire to spread out because of the natural branch pruning and the accumulation of the cuts, while it is increasing the amount of the dead plant in the area where the canopy density is high. It is also observed that slope between $8-35 \%$ can cause large forest fires from previous fires (Akkaş et al., 2006). In light of these information, the GIS maps showing the canopy densities and slopes in the study area were produced (Figure 12 and 13) and their relationship with the fire was evaluated (Figure 14).

As a consequence, the results proved that the regions having canopy density between $71-100 \%$ and slope from $29-41 \%$ were mostly burned in the area (Figure 14).

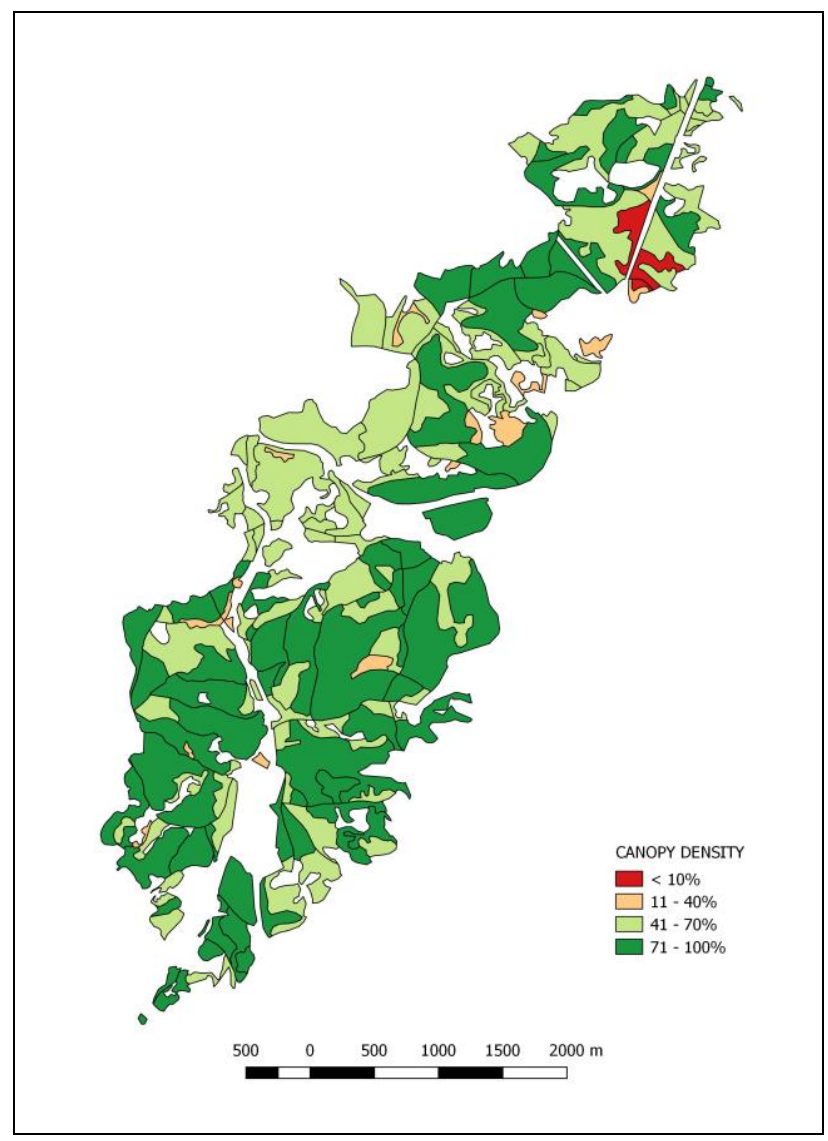

Figure 12. Canopy density map of the Menderes area.

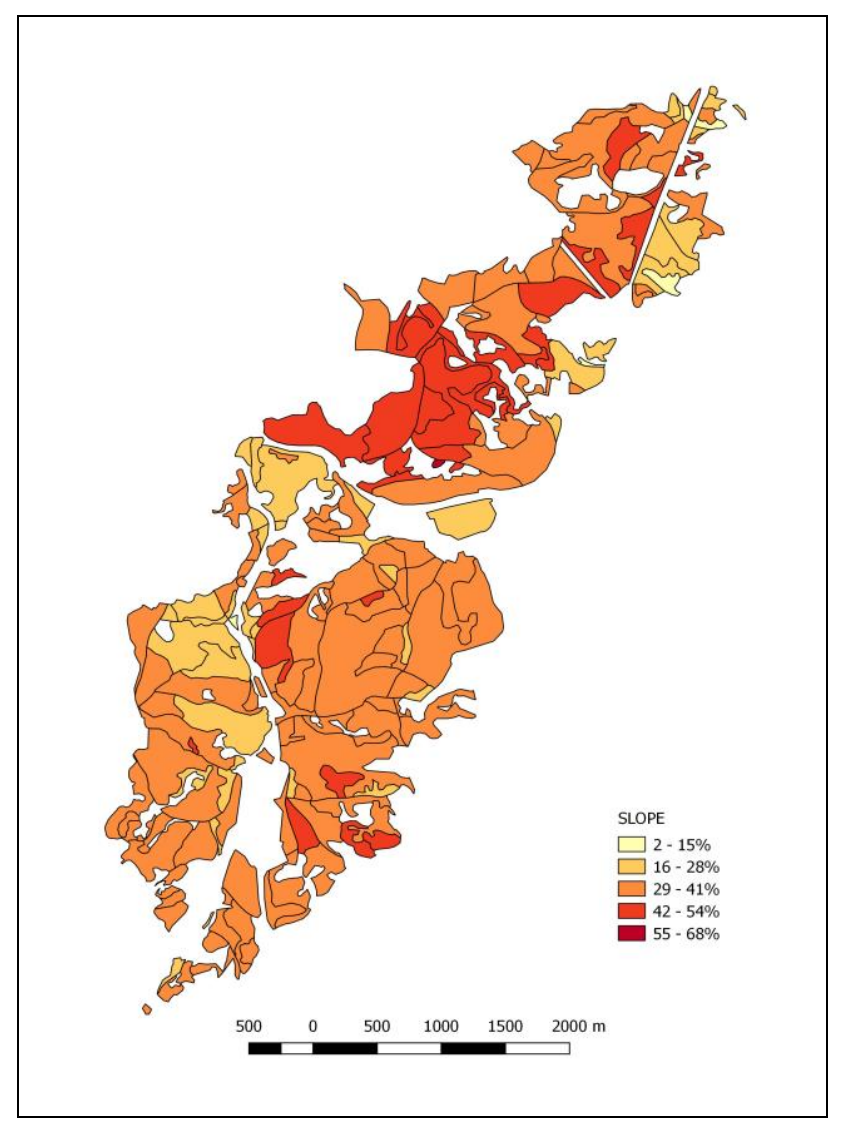

Figure 13. Slope map of the Menderes area.

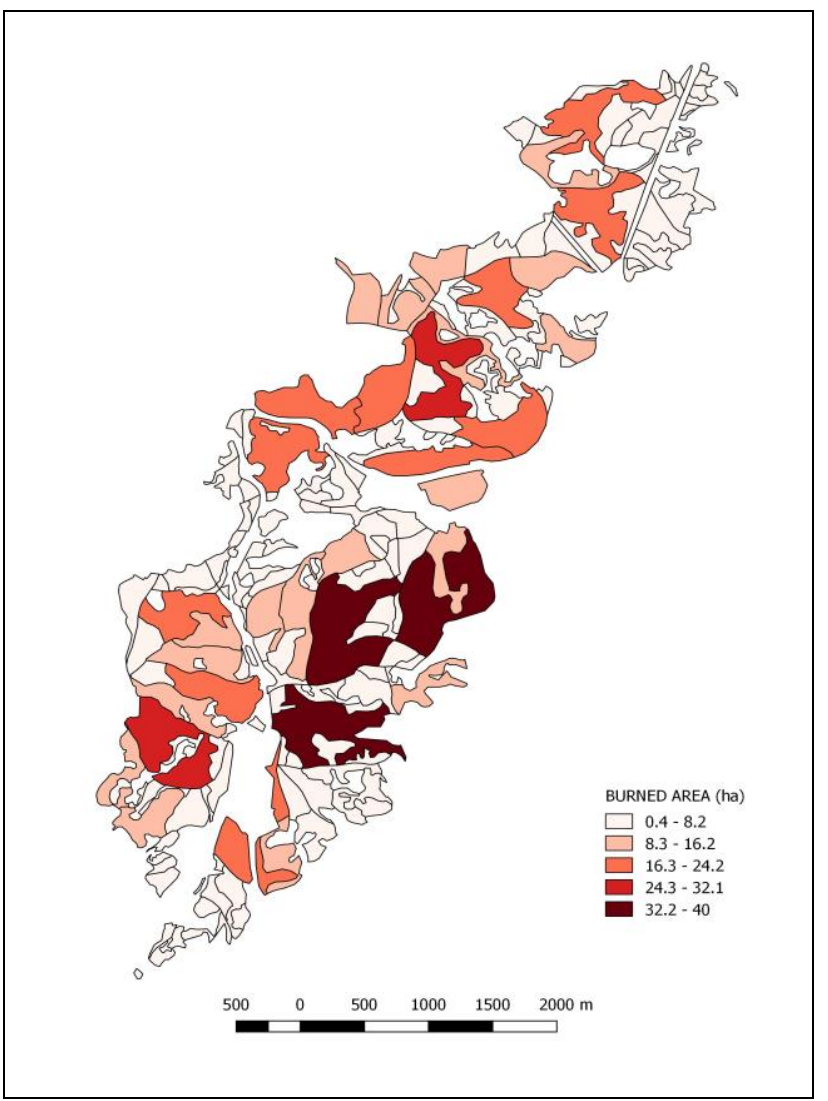

Figure 14 . The impact of canopy density and slope on burned forest areas. 


\section{CONCLUSION}

An integrated analysis of remote sensing and Geographic Information Systems data is very helpful for accurate forest fire mapping. Remote sensing enables to monitor, estimate, map and evaluate the ecological effects of fires (Lentile et al., 2006). On the other hand, GIS gives the opportunity to reveal the relationship between the fire and environment using new techniques and produced fire hazard models for addressing the environmental issues. Hence the necessary precautions to prevent or eliminate the environmental, social, and economical problems caused by the fire can be taken.

From past to present, forest fires become one of Turkey's most important environmental problems. The nearly 25000 forest fires that have emerged in the last decade also reveal this. In this study, the effectiveness of the Sentinel $2 \mathrm{~A}$ and Landsat 8 satellite images to map the forest burned areas demonstrated by the integration of the GIS data taken by the General Directorate of Forestry. The results of the Maximum Likelihood classification of satellite images having different spatial resolutions $(10 \mathrm{~m}, 20 \mathrm{~m}$, and $30 \mathrm{~m})$ showed the effect of the spatial resolution on the classification accuracy (i.e. best accuracy was achieved using Sentinel data $(10 \mathrm{~m})$. The success of the spectral indices (BAI, MIRBI, and NBRT) in distinguishing the burned area from the unburned areas was also monitored. As shown that burned forest area and mine areas are mixed only in the NBR index. Furthermore, it was demonstrated and also mapped how a forest fire is being effected by and/or interrelated with both topographic (canopy density, slope and vegetation type) and meteorological conditions (weather temperature, wind speed, and relative humidity) using remote sensing and GIS integration. As a result, for the protection and sustainability of the forest areas besides the raising the awareness, the forestry sector should follow, develop and use space techniques such as remote sensing and GIS together with new comprehensive fire models for an efficient forest management.

\section{ACKNOWLEDGEMENTS}

We wish to thank Mr. Şahin Aybal and Mr. Yusuf Görmez, Izmir Forestry Chief Directorate for GIS data supply and support.

\section{REFERENCES}

Akkaş, M.E., Bucak, C., Boza, Z., Eronat, H., Bekereci, A., Erkan, A., and Cebeci, C., 2006. Büyük orman yangınlarının meteorolojik verilerin 1 şığında incelenmesi [The investigation of the great wild fires based on meteorological data]. https://www.cem.gov.tr/erozyon/files/erozyon/yardop.../yangin_ meteoroloji_iliskisi_2.doc

Başaran, M.A., Sarıbaşak, H., Cengiz, Y., 2004. Yangın söndürme planı temel esaslarının belirlenmesi (Manavgat Örneği), [Determination of the basis of fire extinguishing plan: A case study of Manavgat]. Batı Akdeniz Ormancılık Araştırma Enstitüsü, Teknik Bülten No: 18.

https://www.ogm.gov.tr/Baskanliklar/DisIliskilerEgitimveArasti rma/Documents/TekSayfalar/Manavgat\%20Yang\%C4\%B1n.pdf

General Directorate of Forestry, 2017.

https://www.ogm.gov.tr/ekutuphane/Sayfalar/Istatistikler.aspx
Gonçalves A.C., and Sousa, A.M.O., 2017. The Fire in the Mediterranean Region: A Case Study of Forest Fires in Portugal, Mediterranean Identities - Environment, Society, Culture, Prof. Borna Fuerst-Bjeliš (Ed.), InTech. https://doi.org/10.5772/intechopen.69410.

Holden, Z.A., Smith, A.M.S., Morgan, P., Rollins, M.G., and Gessler, P.E., 2005. Evaluation of novel thermally enhanced spectral indices for mapping fire perimeters and comparisons with fire atlas data. International Journal of Remote Sensing, 26(21), pp. 4801-4808. https://doi.org/10.1080/01431160500239008

Kääb, A., Winsvold, S.H., Altena, B., Nuth, C., Nagler, T., and Wuite, J., 2016. Glacier remote sensing using sentinel-2. part 1: radiometric and geometric performance, and application to ice velocity. Remote Sensing, 8(7), p. 598. https://doi.org/10.3390/rs8070598

Key, C.H., and Benson, N.C., 2005. Landscape assessment (LA) sampling and analysis methods. In book: FIREMON: Fire Effects Monitoring and Inventory System. Edition: Gen. Tech. Rep. RMRS-GTR-164. Publisher: USDA Forest Service, Rocky Mountain Research Station, Ogden, UT. (Editors: D.C. Lutes, R.E. Keane, J.F. Caratti, C.H. Key, N.C. Benson, S. Sutherland, L.J. Gangi).

https://www.fs.fed.us/postfirevegcondition/documents/publicati ons/FIREMON_LandscapeAssessment.pdf

Lentile, L.B., Holden, Z.A., Smith, A.M.A., Falkowski, M.J., Hudak, A.T., Morgan, P., Lewis, S.A., Gessler, P.E., and Benson, N.C., 2006. Remote sensing techniques to assess active fire characteristics and post-fire effects. International Journal of Wildland Fire, 15(3), pp. 319-345.

Ribeiro, G.A., Araujo, G., Silva, C.M.S., and Magalhaes, M.A., 2014. Relationship between the slope and some variables of fire behavior.

https://digitalis-dsp.uc.pt/bitstream/10316.2/34116/1/978-98926-0884-6_45.pdf?ln=pt-pt

Schepers, L., Haest, B., Veraverbeke, S., Spanhove, T., Borre, J.V., and Goossens, R., 2014. Burned area detection and burn severity assessment of a heathland fire in belgium using airborne imaging spectroscopy (apex). Remote Sensing, 6(3), pp. 1803-1826. https://doi.org/10.3390/rs6031803

Sunar, F., and Özkan, C., 2001. Forest fire analysis with remote sensing data. International Journal of Remote Sensing, 22(12), pp. 2265-2277. https://doi.org/10.1080/014311601300229818

Verbyla, D.L., 2000. Satellite remote sensing of natural resources. Florida: CRC Press LLC 